\title{
O PERFIL E A TRAJETÓRIA DOS BACHARÉIS E TECNÓLOGOS DA ÁREA DE GERENCIAMENTO E ADMINISTRAÇÃO: ESTUDO COMPARATIVO
}

\author{
THE PROFILE AND THE TRAJECTORY OF THE BACHELORS AND \\ TECHNOLOGISTS OF THE MANAGEMENT AND ADMINISTRATION AREA: \\ COMPARATIVE STUDY
}

\section{Recebimento:24/11/2017- Aceite: 09/01/2018- Publicação: 28/01/2018 \\ Processo de Avaliação: Double Blind Review}

Carlos Vital Giordano ${ }^{1}$

Doutor em Ciências Sociais

Professor do Mestrado em Educação do Centro Paula Souza

giordanopaulasouza@yahoo.com.br

Sandra Matos

Mestre em Educação

Centro Paula Souza

sandmatos19@hotmail.com

Luiz Cláudio Gonçalves

Doutor em Engenharia de Produção

Professor da Fatec Zona Sul

luizgoncalves@uol.com.br

\section{RESUMO}

A presente pesquisa apresenta como tema os Bacharéis e Tecnólogos da área de Gerenciamento e Administração graduados em instituições de ensino superior privadas do Estado de São Paulo, que utilizam o custo praticado em suas mensalidades para atrair novos discentes. Objetiva comparar o perfil e a trajetória de profissionais que concluíram Cursos de Bacharelado e, igualmente, aqueles que concluíram Cursos Superiores de Tecnologia na área de Gerenciamento e Administração, entre os anos de 2004 e 2015. Consideraram-se validos apenas questionários de respondentes graduados em instituições que anunciavam valores de mensalidades próximos ao salário mínimo de 2016, ou ofertavam bolsas de estudo e descontos para atrair novos estudantes. Os resultados comprovaram que o grau acadêmico de ensino superior promove diferenciação na carreira dos egressos da área de Gerenciamento e Administração.

Palavras-chave: Gerenciamento; Administração; Tecnólogos; Bacharel; Educação; Profissional.

\footnotetext{
${ }^{1}$ Autor para correspondência: Centro Paula Souza - Rua dos Andradas, 140 - Santa Ifigênia 01208-000 - São Paulo - SP, Brasil.
}

Revista ENIAC Pesquisa, Guarulhos (SP), V.7, n.1, jan.- jun. 2018. 


\section{ABSTRACT}

The present research presents as subject the Bachelor and Technologists of the area of Management and Administration graduated in private higher education institutions of the State of São Paulo, that use the cost practiced in their monthly fees to attract new students. It aims to compare the profile and trajectory of professionals who completed Bachelor's Degree courses and also those who completed Higher Technology Courses in the area of Management and Administration between 2004 and 2015. Only questionnaires of respondents graduated in Institutions that announced monthly tuition values close to the 2016 minimum wage or offered scholarships and discounts to attract new students. The results showed that the academic degree of higher education promotes differentiation in the career of graduates in the area of Management and Administration.

Keywords: Management; Administration; Technologists; Bachelor; Professional; Education.

\section{INTRODUÇÃO}

A expansão do ensino superior, ocorrida no final do século 20 e início do século 21, tornou-se o tema de debates acadêmicos frequentes. Entre as questões abordadas estão: a interação com o mercado de trabalho, a ênfase nas instituições privadas, o aumento do número de cursos de diferentes graus acadêmicos, bem como, o significado do ensino superior para o indivíduo e para a sociedade.

O número de Instituições de Ensino Superior (IES) no Brasil passou de 894 em 1995 para 2.368 em 2014, segundo o último censo da Educação Superior realizado até a finalização desta pesquisa. Este aumento teve ênfase nas instituições privadas que apresentaram crescimento de $202,63 \%$, enquanto o setor público teve aumento de $41,90 \%$ (INEP, 2014; RISTOFF, 2013).

Este crescimento foi consequência de uma trajetória histórica. Analisando a educação superior pública e privada entre 1808 e 2000, Durham (2005) já indicava que o sistema privado dividiu-se em dois segmentos: comunitário ou confessional, que se assemelhava ao setor público; e um segmento empresarial, que se orientou para satisfazer demandas sociais mais imediatas, concentrando-se na oferta de cursos de baixo custo e no estabelecimento de exigências acadêmicas menores.

Em pesquisa mais recente, Prates e Silva (2014) analisaram os efeitos do tipo de instituição de ensino superior sobre os egressos e verificaram que a expansão ocorreu alicerçada em instituições privadas que adotaram o modelo de gestão próprio das organizações empresariais.

Revista ENIAC Pesquisa, Guarulhos (SP), V.7, n.1, jan.- jun. 2018. 
Os diferentes custos ofertados, aliados às ofertas de bolsas vinculadas a programas de governo, tais como: o Programa Universidade Para Todos (ProUni) e o Fundo de Financiamento Estudantil (FIES), permitiram o acesso ao ensino superior para pessoas de origens sociais e condições econômicas desfavorecidas, ou seja, classes C e D. A geração de melhores oportunidades no mercado de trabalho faria deste cenário o ideal, devido a melhoria da renda, porém, os dados estatísticos mostram desalinhamento com a expansão do ensino superior.

No ano de 2014 verificou-se que Gerenciamento e Administração é a área detalhada com maior concentração percentual de matrículas no ensino superior $(17,23 \%)$. O censo apresenta 78 áreas detalhadas e a Tabela 1 mostra as três áreas com maior concentração de matrículas (INEP, 2014).

Tabela 1 - Três áreas com maior confluência de matrículas em 2014

\begin{tabular}{lcc}
\hline Área detalhada & Matrículas & Percentual (\%) \\
\hline Gerenciamento e administração & 1.348 .616 & 17,23 \\
Direito & 813.454 & 10,39 \\
Ciências da educação & 653.111 & 8,34 \\
\hline
\end{tabular}

Fonte: Dados extraídos da Sinopse do Censo da Educação Superior de 2014

(INEP, 2014)

Dos programas inseridos na área, o Bacharel em Administração é o mais antigo, com mais cursos, maior número de matrículas e concluintes. Bertero (2007), ao descrever o perfil dos estudantes de graduação em administração -em termos de média, mediana ou moda - argumenta que o curso é procurado por aqueles que desejam ou necessitam de diploma universitário, sem que tenham interesse mais genuíno pela profissão de administrador, tornando este mais um curso de educação geral, do que um curso marcado pelo rigor de conteúdo.

Ao cenário de expansão do ensino superior acrescenta-se o crescimento dos Cursos Superiores de Tecnologia. Por meio de estudos da alteração nas legislações que envolvem a educação profissional e os Cursos Superiores de Tecnologia, Takahashi (2010) afirma que o aumento na oferta desta modalidade está vinculado às reformas ocorridas no sistema educacional e às configurações socioeconômicas e políticas do

Revista ENIAC Pesquisa, Guarulhos (SP), V.7, n.1, jan.- jun. 2018. 
Brasil, que buscam alinhar suas estratégias educacionais ao contexto internacional, assim como para sua inserção na economia globalizada.

Neste contexto, o sistema educacional e o mercado de trabalho se deparam com paradigmas e desafios para absorver esses profissionais. A qualidade do ensino e as oportunidades profissionais são constantemente questionadas, portanto, torna-se relevante o estudo comparativo entre os profissionais da área de Gerenciamento e Administração formados em diferentes graus acadêmicos em IES privadas, que adotam o modelo de gestão das organizações empresariais e utilizam o preço e os descontos como fator de competitividade para atrair novas matrículas.

Assim, foi elaborada a seguinte questão de pesquisa: $O$ grau acadêmico (Bacharel ou Tecnólogo) de ensino superior do profissional da área de Gerenciamento e Administração, egresso de instituições privadas com gestão de custo competitiva promove diferenciação na carreira, auxiliando na definição do cargo ocupado, do salário e na busca de colocação no mercado de trabalho?

Para responder à questão problema, o objetivo principal desta pesquisa é comparar o perfil e a trajetória de profissionais que concluíram Cursos de Bacharelado e, igualmente, aqueles que concluíram Cursos Superiores de Tecnologia na área de Gerenciamento e Administração IES privadas com vantagem competitiva em seus preços (próximos a $\mathrm{R} \$ 880,00$, em 2016).

\section{REFERENCIAL TEÓRICO}

O referencial teórico se inicia por gerenciamento e administração.

\subsection{GERENCIAMENTO E ADMINISTRAÇÃO}

Inserida nas transformações do ensino superior, a área de Gerenciamento e Administração sofreu gradativo crescimento. O censo da Educação Superior de 2014 apurou que, com 1.348.616 (17,23\%) das matrículas no ensino superior, é a área que detém a maioria dos estudantes de graduação (INEP, 2014).

O ensino superior, desde a criação dos primeiros cursos, passou por diversas reformas. A mais recente delas, a LDB $n^{\circ}$ 9.394/96, viabilizou a Portaria $n^{\circ} 1.647$, instituída em 25 de novembro de 1999, a qual definiu os procedimentos para o credenciamento de centros de educação tecnológicos e a autorização de cursos de nível tecnológico da educação profissional (BRASIL, 1999). A partir deste momento, a área de

Revista ENIAC Pesquisa, Guarulhos (SP), V.7, n.1, jan.- jun. 2018. 
Gerenciamento e Administração, que já se expandia anualmente com os cursos de Bacharelado, passou a fazer parte deste grau acadêmico.

De acordo com Bertero (2006), a administração, e suas diversas opções de empresas públicas e privadas, foi a área de ensino que assumiu maior dimensão no Brasil e que se desdobrou em especificidades funcionais e de setores como marketing, finanças, hospitais, turismo, pequenas e médias empresas.

Desde o surgimento dos Cursos Superiores de Tecnologia na área de Gerenciamento e Administração, houve constante crescimento no número de cursos. Porém, conforme mostra o Gráfico 1, o percurso do número de programas (nomenclaturas), entre o ano 2000 e 2014, foi instável. Inicialmente ocorre a crescente criação de novos programas, com significativa redução nos anos de 2007 e 2008. No ano seguinte tem-se a retomada seguida de outra baixa de 67,38\% em 2010 e aparente estabilidade até o ano de 2014.

Entre os anos 2000 e 2014 o número de cursos na área de Gerenciamento e Administração (Bacharelado e Tecnologia) teve aumento de 327,91\%, com evolução representativa no setor público $(259,62 \%)$ e privado $(340,70 \%)$. Porém, a predominância de cursos no setor privado, em alguns anos, é superior a 90\%, conforme mostra a Tabela 3. No contexto geral do ensino superior, no mesmo período, as IES privadas detêm entre $70 \%$ e $75 \%$ dos cursos.

\subsubsection{Bacharel em Administração}

Entre os cursos da área de Gerenciamento e Administração, o Bacharel em Administração é o pioneiro e conta com a predominância do número de cursos e matrículas. Sua expansão esteve bastante vinculada à expansão do ensino superior na década de 1970 e, mais tarde, após a década de 2000.

Oliveira e Sauerbronn (2007) afirmam que a discussão em torno dos principais desafios que a área de administração enfrenta no início do século 21 expõe a necessidade de considerar as principais tendências para uma possível transformação no ensino superior. O curso de bacharelado em Administração de Empresas manteve a tendência de crescimento desordenado dos cursos de graduação.

Ainda, a privatização teve sérias implicações para a expansão do ensino superior. Em pesquisas, Bertero (2007) constatou que na área de administração o número de vagas ofertadas fez com que a lista de inscritos se tornasse a lista de matrículas. O alvo dessa

Revista ENIAC Pesquisa, Guarulhos (SP), V.7, n.1, jan.- jun. 2018. 
expansão, para a desejada inclusão dos brasileiros na educação universitária, foi a classe média baixa e mesmo a classe baixa.

Tais cursos passaram a ser frequentados pelo público que aspirava ter acesso às funções econômico-administrativas em empresas públicas ou privadas, e aqueles que já desenvolviam tais atividades no mercado profissional e passaram a se sentir estimulados ou pressionados a buscar o título universitário para obter melhoria de cargo ou salário ou mesmo para manter-se no mercado.

Para Paula e Rodrigues (2006), quando se examina o panorama do ensino da Administração no Brasil e no mundo é possível notar algumas tendências semelhantes no que se refere à "mercantilização" do ensino. Bertero (2007) entende que a situação de massificação, implica mudanças nos objetivos da universidade, no perfil do alunado e, consequentemente, nas competências exigidas do professor.

\subsubsection{Cursos superiores de tecnologia da área de gerenciamento e administração}

Em 2000 surgiram os primeiros Cursos Superiores de Tecnologia (CST) da área de Gerenciamento e Administração, 32 anos após a reforma universitária e a Lei $\mathrm{n}^{\circ}$ 5.540/68 que permitiu o surgimento dos primeiros CSTs. No Censo da Educação Superior, em 2014, estes cursos representavam 57,16\% dos cursos superiores da área de Gerenciamento e Administração, 38\% dos CSTs e 7,68\% dos cursos superiores no Brasil (INEP, 2014).

No ano de 2014, dos 4.232 cursos superiores da área de Gerenciamento e Administração, $57 \%$ eram CST. O tópico 2.2, abordado mais à frente, é dedicado à história e objetivos dos CST, enquanto este tópico explana sobre os cursos inseridos na área de Gerenciamento e Administração. Também em 2014, o Censo da Educação Superior identificou que $37,72 \%$ dos CST estão na área de Gerenciamento e Administração. Estes 2.419 cursos constam com 519.866 matrículas e 91,4\% destes são ministrados por IES privadas. O estado de São Paulo tem a maior concentração que é a de $35,6 \%$.

\subsection{POLÍTICAS PÚBLICAS E A EXPANSÃO DO ENSINO SUPERIOR}

Desde os anos 2000 o Brasil presenciou o aumento de todos os números que envolvem o ensino superior (instituições, matrículas, cursos, ingressantes e concluintes). Ao analisar os dados dos cursos de graduação entre 1991 e 2011, Ristoff (2013) afirma que o sistema de educação superior está em permanente expansão, em diferentes níveis

Revista ENIAC Pesquisa, Guarulhos (SP), V.7, n.1, jan.- jun. 2018. 
de aceleração, de acordo com diversos fatores de influência. Os anos que se seguiram à promulgação da atual LDB 9.394/96 (1996 a 2005), a abertura de novos cursos teve seu maior crescimento, que foi de $209,9 \%$.

Em ordem cronológica, O Quadro 1 apresenta as Leis, Decretos e alterações que contribuíram para a expansão do Ensino Superior.

Quadro 1: Cronologia das Principais Políticas Públicas voltadas para a expansão do Ensino Superior

\begin{tabular}{|c|c|}
\hline Data & Política Pública \\
\hline 1994 & $\begin{array}{l}\text { Extinção do Conselho Federal de Educação (CFE) e instituição do } \\
\text { Conselho Nacional de Educação (CNE), conferindo ao MEC maior } \\
\text { autonomia na condução do processo de expansão do ensino de } \\
\text { graduação. }\end{array}$ \\
\hline 2001 & $\begin{array}{l}\text { A Lei } 10.260 \text { de } 12 \text { de julho de } 2001 \text { regulamentou o Fundo de } \\
\text { Financiamento ao Estudante de Ensino Superior (FIES). }\end{array}$ \\
\hline 2004 & Institucionalização do ProUni pela Lei 11.096 de 13 de janeiro de 2005. \\
\hline 2005 & $\begin{array}{l}\text { O FIES passou a oferecer financiamento parcial de até } 50 \% \text { para alunos } \\
\text { que tinham os outros } 50 \% \text { financiados pelo ProUni). }\end{array}$ \\
\hline 2007 & $\begin{array}{l}\text { Criação do REUNI pelo Decreto Presidencial n }{ }^{\circ} \text { 6.096, de } 24 \text { de abril } \\
\text { de } 2007\end{array}$ \\
\hline 2010 & $\begin{array}{l}\text { Com o objetivo de ampliar o acesso ao ensino superior e aumentar o } \\
\text { número de estudantes interessados foram implementadas mudanças no } \\
\text { FIES, entre elas a possibilidade de solicitar o financiamento a qualquer } \\
\text { tempo durante o ensino superior. }\end{array}$ \\
\hline
\end{tabular}

Fonte: Elaborado pelos autores, 2017.

Para Barbosa (2014) a expansão do ensino superior vem acompanhada de intenso processo de diversificação, que pode ser vista sob dois ângulos principais: a diversificação substantiva dos percursos escolares (novos objetivos, teorias, áreas de formação), mas, também, a diversificação burocrática e social, com a criação de novos tipos de diplomas por meio das mudanças ocorridas no reconhecimento da educação profissional. Em um país com níveis muito baixos de escolarização estes pontos se tornam particularmente importantes.

Revista ENIAC Pesquisa, Guarulhos (SP), V.7, n.1, jan.- jun. 2018. 


\subsection{EDUCAÇÃO PROFISSIONAL E OS CURSOS SUPERIORES DE TECNOLOGIA}

A Educação Profissional e Tecnológica passou a ter novos olhares nas últimas décadas e, de acordo com Peterossi (2014), está sendo incorporada pelo debate educacional, deixando de ter lugar marginal. O saber tecnológico e a Educação

Profissional transformaram-se em investimento econômico estratégico tornando-se fatores determinantes das relações de produção.

Takahashi e Amorim (2008) enfatizam que, sempre associada à formação de classes menos favorecidas, o preconceito sobre a educação profissional e tecnológica começou a ser mitigado somente nos últimos anos por meio da Constituição Federal de 1988 e da LDB n 9.394/96. Enquanto promotora da inserção no mercado de trabalho e da inclusão social, a Educação Profissional tangencia outros importantes tópicos como o desenvolvimento da Economia Baseada no Conhecimento $(\mathrm{EBC})$ e a difusão de um Sistema Nacional de Inovação (SNI).

Dentre as três modalidades do ensino profissional - básico, técnico e tecnológico - a educação profissional tecnológica de graduação e pós-graduação, assume o caráter específico e próprio. Essas modalidades visam à qualificação e requalificação de acordo com as novas necessidades do mercado de trabalho, e são suportadas pelo surgimento das novas tecnologias, exigidas pela globalização econômica que, por sua vez, demanda do trabalhador novas competências e habilidades (TAKAHASHI; AMORIM, 2008).

Em 2001, por meio do Parecer CNE/CES nº 436, a Câmara de Educação Superior, do Conselho Nacional de Educação, procurou definir - ao mesmo tempo em que fez considerações sobre a autorização e o reconhecimento dos cursos de formação de tecnólogos - em qual modalidade de curso superior, entre os previstos no artigo 44 da LDB, melhor se enquadravam os cursos de formação de tecnólogos: cursos de graduação ou cursos sequenciais (BRASIL, 2001).

Para Barbosa (2014, p. 57) “os CSTs expressam de forma clara as duas vertentes dessa modernização: significam tanto uma diversificação no conteúdo da formação quanto um rearranjo institucional". Tanto a lista de atividades para as quais os tecnólogos se sentem habilitados, quanto à visão da empresa sobre esses profissionais evidenciam o forte caráter prático de sua formação e das expectativas quanto ao seu trabalho.

Revista ENIAC Pesquisa, Guarulhos (SP), V.7, n.1, jan.- jun. 2018. 


\subsection{O ENSINO SUPERIOR PRIVADO}

O caráter tardio e o desenvolvimento precoce e majoritário do sistema de ensino privado paralelo ao público são características que tornam o Brasil um caso singular no mundo, com relação ao desenvolvimento do ensino superior (SAMPAIO, 2014; DURHAM, 2005). Ristoff (2013) identificou que as IES privadas, nas décadas de 1990 e 2000, foram as principais responsáveis pela formação dos profissionais de nível superior no país.

Entre as discussões que envolvem a expansão do ensino superior no Brasil está seu significado para o indivíduo e para a sociedade. Barbosa (2014), ao analisar dados de pesquisas que relacionam nível de escolaridade e remuneração, afirma que há evidências de que as qualificações pagam bem, porém, de maneira desigual. Desta forma, existem sinais de que benefícios pessoais com maior educação estão se tornando mais importantes.

Para descrever o principal público-alvo das IES privadas, Almeida (2015) cita o surgimento do expressivo contingente que foi classificado como uma nova "classe econômica" - a nova classe C - na primeira década dos anos 2000. Segundo o autor, um dos principais anseios dessa população, marcada por restrições de cunho financeiro e competitivo na disputa pelas vagas no ensino superior público, é a busca da elevação de nível social, a partir da obtenção do diploma do ensino superior.

Por meio de análises do Censo de 2010, Reis e Machado (2015) concluem que indivíduos com formação superior possuem rendimento três vezes maior em comparação com os demais trabalhadores, com níveis mais baixos de escolaridade. No entanto, os rendimentos no mercado de trabalho também podem variar de acordo com o tipo de curso superior escolhido pelo trabalhador.

Analisando estudantes do ProUni, Almeida (2012) identifica que, entre os entrevistados, os qualificados como bacharelandos, principalmente aqueles das universidades confessionais (Mackenzie e Pontifícia Universidade Católica de São Paulo), possuíam melhores condições culturais e econômicas quando comparados aos tecnólogos e licenciados. Esta verificação demonstra a influência de fatores sociais na escolha da formação e da instituição.

Revista ENIAC Pesquisa, Guarulhos (SP), V.7, n.1, jan.- jun. 2018. 


\section{MÉTODO}

Para coleta de dados estabeleceu-se o filtro entre 2004 e 2015. Os CSTs surgiram no ano 2000, requerendo intervalo para a formação das primeiras turmas. A realização da coleta de dados, em outubro de 2016, permitiu ter egressos formados até o ano de 2015, uma vez que estes já estavam matriculados no período pesquisado.

Obteve-se 90 questionários válidos, sendo 45 de cada grau acadêmico (Bacharel e Tecnólogo). Entre os Tecnólogos obteve-se retorno de 4 diferentes formações, detalhamento na Figura 1.

Figura 1 - Distribuição dos questionários devolvidos

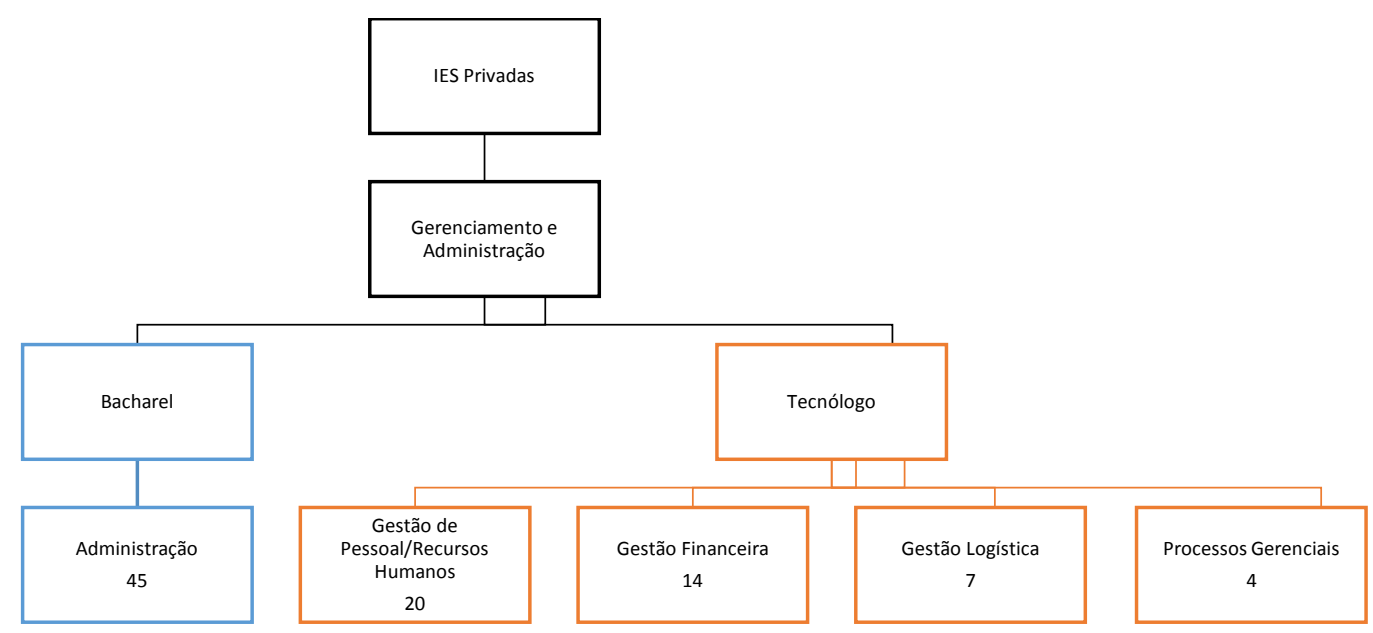

Fonte: Elaborada pelos autores, 2017.

A pesquisa exploratória descritiva examinou o tema utilizando o método de análise quantitativa e os dados interpretados de acordo com a pergunta e os objetivos propostos, limitando-se, todavia, as considerações finais à amostra coletada.

\section{RESULTADOS E DISCUSSÃO}

No tocante à distribuição por gênero, os resultados mostram que 61,0\% das respondentes eram do gênero feminino e 39,0\% do sexo masculino.

Iidentificou-se que 30\% dos 90 participantes iniciaram o ensino superior até dois anos após o término do ensino médio. Com relação à cultura familiar universitária, identificou-se que 59\% foram os primeiros membros da família a ingressar no ensino superior, sendo que o índice para aqueles que têm pais com ensino superior era de $10 \%$, mães foi de $9 \%$ e $3 \%$ para outros responsáveis diretos.

Revista ENIAC Pesquisa, Guarulhos (SP), V.7, n.1, jan.- jun. 2018. 
Os que possuíam atividade profissional remunerada antes do início do ensino superior representam $98 \%$ dos respondentes. Sobre o financiamento da formação, $54 \%$ foram responsáveis pelo pagamento integral e $22 \%$ pelo pagamento parcial. Os programas de governo, ProUni, FIES e Escola da Família, financiaram parcial ou integralmente a formação de $29 \%$ dos respondentes.

O principal motivador para ingressar no ensino superior foi buscar a melhoria de cargo ou salário (ver Gráfico 1). Embora o nível de insatisfação seja relevante, o curso não atendeu ou atendeu parcialmente as expectativas de $38 \%$ dos respondentes e apenas um afirmou que a formação não gerou qualquer benefício.

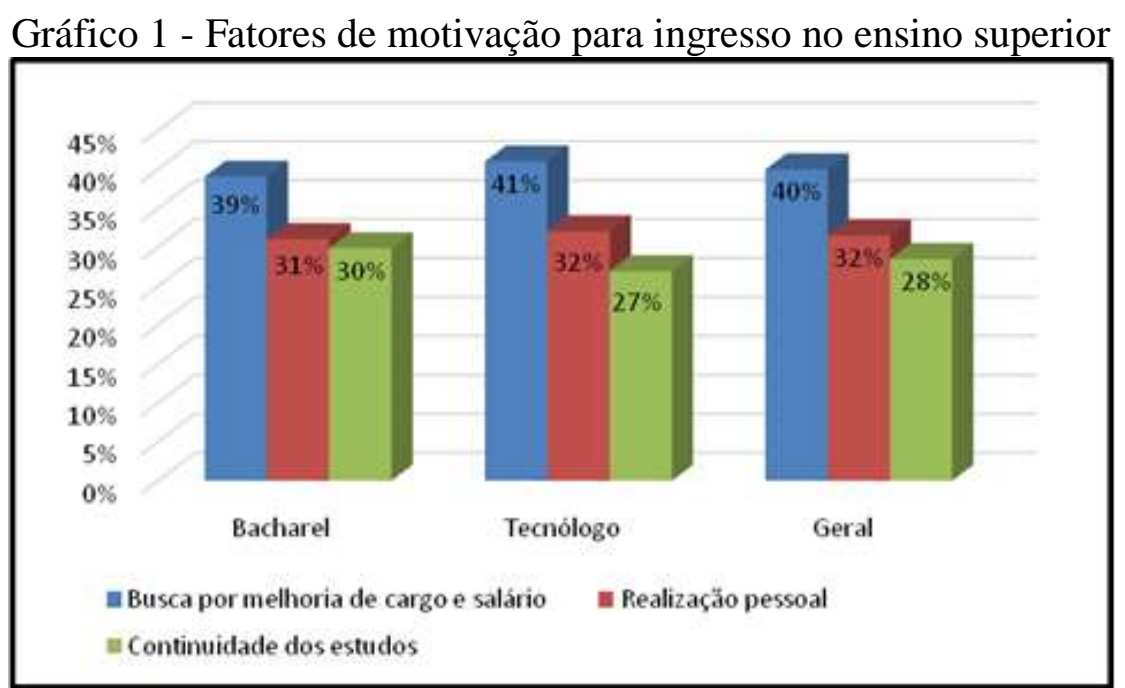

Fonte: Elaborado pelos autores, 2017

Dos respondentes, $78 \%$ afirmaram que tiveram melhoria de cargo ou posição após a formação (ver Tabela 2).

Tabela 2 - Melhoria de cargo/posição após formação

\section{Melhoria de cargo/posição profissional}

\section{Titulação}

Bacharel Tecnólogo

\begin{tabular}{lcccc}
\hline Sim. Dentro da mesma empresa & 20 & 17 & 37 & 41 \\
Sim. Por meio de troca de empresa & 17 & 16 & 33 & 37 \\
Não & 8 & 12 & 20 & 22 \\
\hline Total & 45 & 45 & 90 & 100 \\
\hline
\end{tabular}

Fonte: Elaborada pelos autores, 2017.

Revista ENIAC Pesquisa, Guarulhos (SP), V.7, n.1, jan.- jun. 2018. 
Para comparar os cargos ocupados e verificar as diferenças, foram atribuídos valores, conforme Tabela 3, para cálculo do intervalo de confiança.

Tabela 3 - Atribuição de valores aos cargos

\begin{tabular}{lccc}
\hline \multirow{2}{*}{ Cargo } & Valor & \multicolumn{2}{c}{ Titulação } \\
\cline { 3 - 4 } & & Bacharel & Tecnólogo \\
\hline Auxiliar ou similar & 1,0 & 4 & 3 \\
Assistente ou similar & 2,0 & 9 & 17 \\
Analista ou similar & 3,0 & 15 & 16 \\
Supervisor ou similar & 4,0 & 2 & 5 \\
Coordenador ou similar & 5,0 & 6 & 2 \\
Gerente ou similar & 6,0 & 6 & 2 \\
Empresário/ Empreendedor/ & 7,0 & 2 & - \\
Proprietário & 8,0 & 1 & - \\
Diretor ou similar & & & \\
\hline
\end{tabular}

Fonte: Elaborada pelos autores com base nos resultados da pesquisa, 2017.

Após a distribuição entre os cargos realizou-se o cálculo dos intervalos de confiança tanto para o título de Bacharel como de Tecnólogo apresentado na Tabela 4. Embora o intervalo de confiança dos cargos ocupados pelos Tecnólogos coincida em 0,07 $(3,16-3,09)$ com os Bacharéis, considerou-se que existe diferença de cargos entre os graus acadêmicos com vantagem para os Bacharéis.

Tabela 4 - Intervalo de confiança dos cargos

\begin{tabular}{lccccccc}
\hline $\begin{array}{c}\text { Grau } \\
\text { Acadêmico }\end{array}$ & N & Alfa & Média & DP & IC & IC- & IC+ \\
\hline Bacharéis & 45 & $5 \%$ & 3,62 & 1,81 & 0,53 & $\mathbf{3 , 0 9}$ & $\mathbf{4 , 1 5}$ \\
Tecnólogos & 45 & $5 \%$ & 2,82 & 1,15 & 0,34 & $\mathbf{2 , 4 9}$ & $\mathbf{3 , 1 6}$ \\
\hline
\end{tabular}

Fonte: Elaborada pelos autores, 2017.

Processo semelhante foi utilizado para comparar os salários. O valor atribuído para cada faixa salarial foi a média, com exceção da primeira que vai até dois salários mínimos. A Tabela 5 permite melhor compreensão dos valore atribuídos.

Revista ENIAC Pesquisa, Guarulhos (SP), V.7, n.1, jan.- jun. 2018. 
Tabela 5 - Atribuição de valores as faixas salariais

\begin{tabular}{|c|c|c|c|}
\hline \multirow{2}{*}{ Faixa salarial } & \multirow{2}{*}{ Valor } & \multicolumn{2}{|c|}{ Titulação } \\
\hline & & Bacharel & Tecnólogo \\
\hline Até 2 salários & 2,0 & 7 & 15 \\
\hline Acima de 2 até 4 & 3,0 & 16 & 22 \\
\hline Acima de 4 até 7 & 5,5 & 12 & 7 \\
\hline Acima de 7 até 10 & 8,5 & 8 & 1 \\
\hline Acima de 10 até 20 & 15,0 & 2 & - \\
\hline
\end{tabular}

Fonte: Elaborada pelos autores, 2017.

A análise do intervalo de confiança dos salários de Bacharéis e Tecnólogos, descrita na Tabela 6, não identificou coincidências entre os dois. Comprovou-se que existe vantagem salarial dos Bacharéis em relação aos Tecnólogos.

Tabela 6 - Intervalo de confiança dos salários

\begin{tabular}{lccccccc}
\hline Grau Acadêmico & n & Alfa & Média & DP & IC & IC- & IC+ \\
\hline Bacharéis & 45 & $5 \%$ & 5,02 & 3,12 & 0,91 & $\mathbf{4 , 1 1}$ & $\mathbf{5 , 9 3}$ \\
Tecnólogos & 45 & $5 \%$ & 3,18 & 1,41 & 0,41 & $\mathbf{2 , 7 7}$ & $\mathbf{3 , 5 9}$ \\
\hline
\end{tabular}

Fonte: Elaborada pelos autores, 2017.

Para finalizar a análise de poder de escolha no mercado de trabalho, utilizou-se o diagrama de Pareto para demonstrar os principais motivadores para as trocas de emprego.

Entre as evidências apresentada nos Gráficos 2 e 3, nota-se que a demissão é o principal fator de troca de emprego entre os Tecnólogos, além de terem o índice para esta resposta superior aos Bacharéis. Embora, a melhoria de salário seja o quarto maior índice de respostas entre os dois graus acadêmicos, entre os Bacharéis representou 16\% das respostas e entre os Tecnólogos, $13 \%$.

O intervalo de confiança apresentado na Tabela 7 mostra que os Tecnólogos ficam em média mais tempo sem ocupação profissional remunerada (anos), mas Bacharéis trocam de emprego com mais frequência, como demonstrado nos Gráficos 2 e 3.

Revista ENIAC Pesquisa, Guarulhos (SP), V.7, n.1, jan.- jun. 2018. 
Tabela 7 - Intervalo de confiança para períodos sem ocupação profissional remunerada

\begin{tabular}{lccccccc}
\hline \multicolumn{1}{c}{ Grau Acadêmico } & n & Alfa & Média & DP & IC & IC- & IC+ \\
\hline Bacharéis & 45 & $5 \%$ & 0,39 & 0,55 & 0,16 & $\mathbf{0 , 2 3}$ & $\mathbf{0 , 5 5}$ \\
Tecnólogos & 45 & $5 \%$ & 0,61 & 0,82 & 0,24 & $\mathbf{0 , 3 7}$ & $\mathbf{0 , 8 5}$ \\
\hline
\end{tabular}

Fonte: Elaborada pelos autores, 2017.

Gráfico 2 - Motivadores para troca de emprego dos Bacharéis

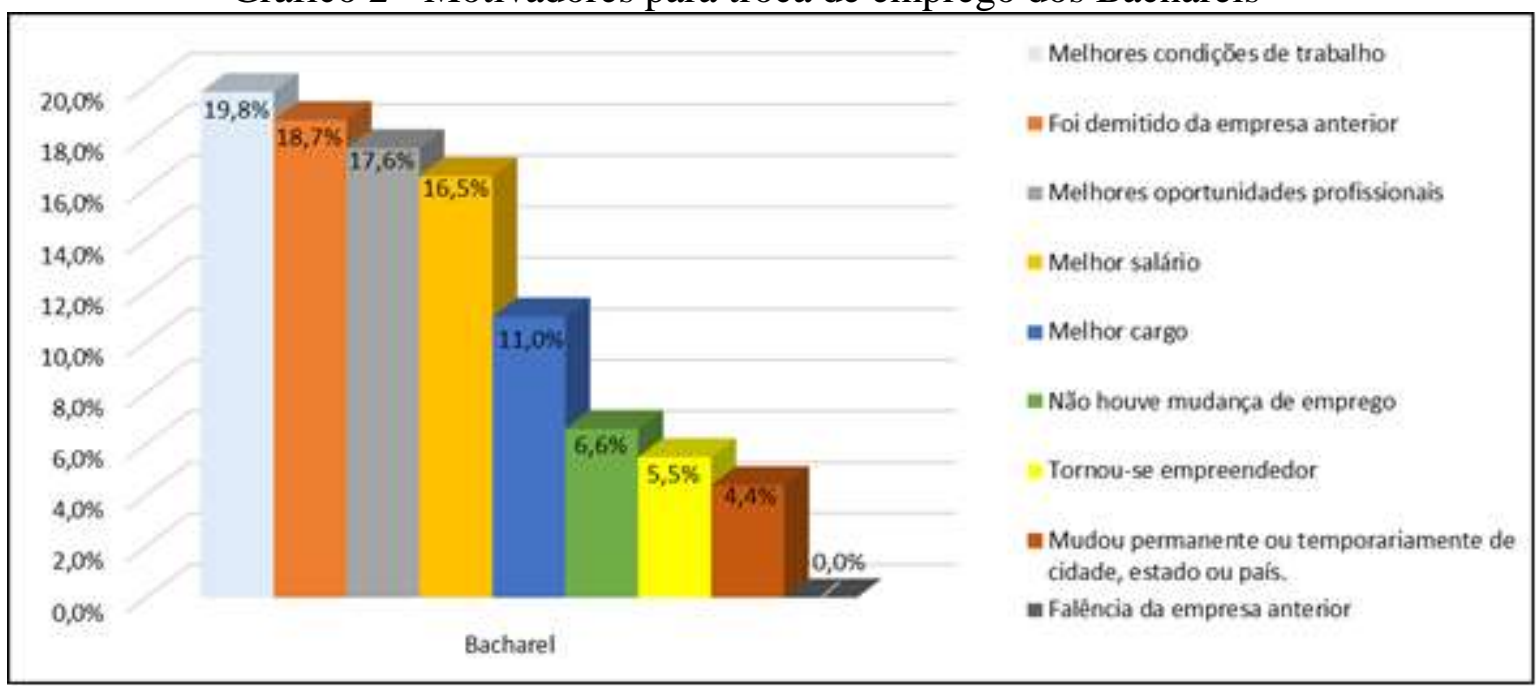

Fonte: Elaborada pelos autores, 2017.

Gráfico 3 - Motivadores para troca de empregos dos Tecnólogos

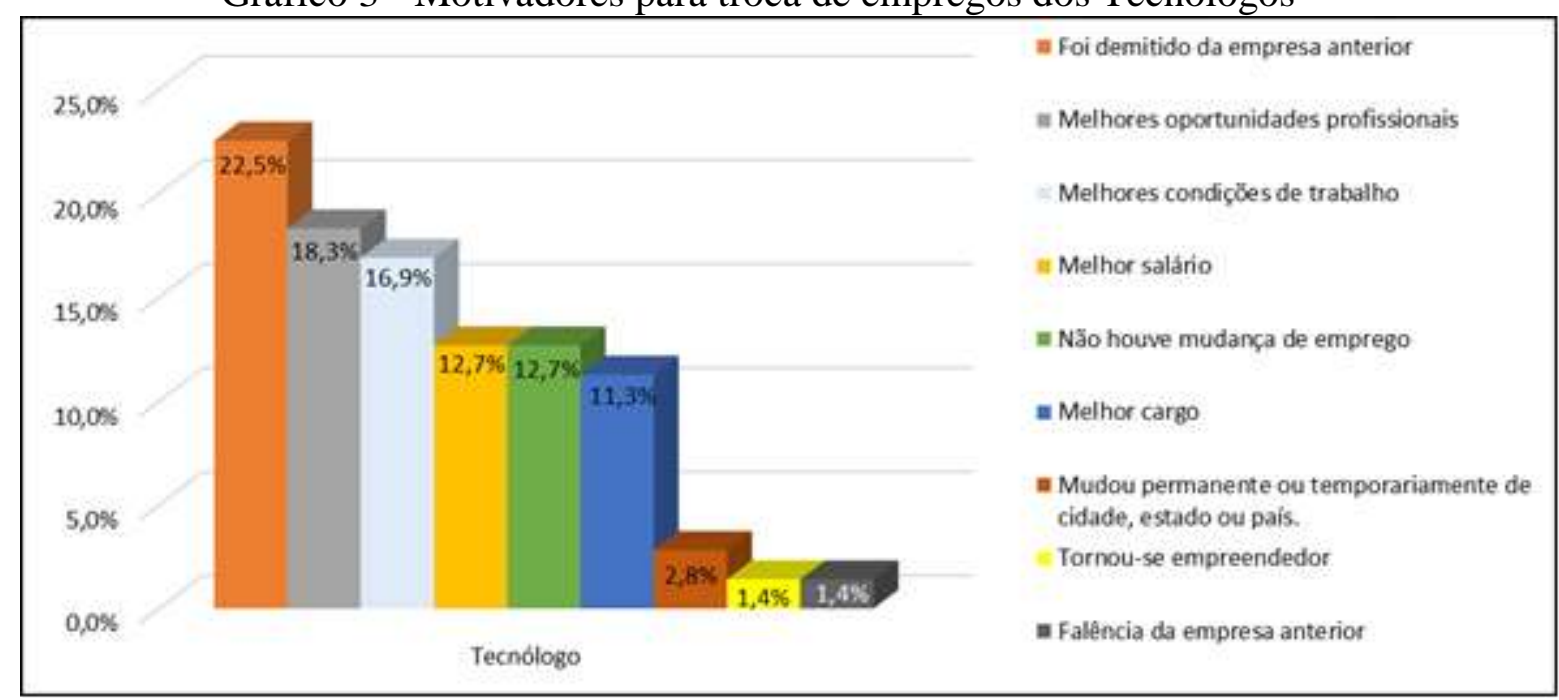

Fonte: Elaborada pelos autores, 2017.

Com o objetivo de verificar fatores externos ao grau acadêmico que provocam alterações na faixa salarial, realizou-se a análise dos intervalos de confianças entre gêneros para os dois graus acadêmicos. O resultado apresentado na Tabela 8 mostrou que,

Revista ENIAC Pesquisa, Guarulhos (SP), V.7, n.1, jan.- jun. 2018. 
para este grupo e esta formação, não existem vantagens salariais por gênero, seja para os Bacharéis ou Tecnólogos, que apresentaram altos níveis de coincidência para os intervalos.

Tabela 8 - Intervalo de confiança de faixa salarial por gênero

\begin{tabular}{lllllllll}
\hline $\begin{array}{c}\text { Grau } \\
\text { Acadêmico }\end{array}$ & Gênero & N & Alfa & Média & DP & IC & IC- & IC+ \\
\hline \multirow{2}{*}{ Bacharéis } & Masculino & 16 & $5 \%$ & 5,3 & 2,58 & 1,26 & $\mathbf{4 , 0 5}$ & $\mathbf{6 , 5 8}$ \\
& Feminino & 29 & $5 \%$ & 4,9 & 3,41 & 1,24 & $\mathbf{3 , 6 2}$ & $\mathbf{6 , 1 0}$ \\
\multirow{2}{*}{ Tecnólogos } & Masculino & 19 & $5 \%$ & 3,2 & 1,78 & 0,80 & $\mathbf{2 , 4 1}$ & $\mathbf{4 , 0 1}$ \\
& Feminino & 26 & $5 \%$ & 3,2 & 1,10 & 0,42 & $\mathbf{2 , 7 3}$ & $\mathbf{3 , 5 8}$ \\
\hline
\end{tabular}

Fonte: Elaborada pelos autores, 2017.

Para verificar a influência da continuidade dos estudos nos salários, foi calculada a média de faixa salarial entre os dois grupos. A Tabela 32 permite observar entre os Bacharéis, somente aqueles que cursaram o segundo Bacharelado não apresentam vantagem salarial em relação aos que não obtiveram outros cursos acadêmicos após a conclusão do ensino superior. Todos os outros cursos acadêmicos de formação ou especialização apresentaram significativa melhoria nos salários.

Tabela 9 - Relação entre outras formações e faixa salarial dos Bacharéis

\begin{tabular}{|c|c|c|c|c|c|c|c|}
\hline \multirow[b]{2}{*}{$\begin{array}{l}\text { Cursos/Formação dos } \\
\text { Bacharéis }\end{array}$} & \multicolumn{5}{|c|}{ Valores* } & \multirow{2}{*}{ Total } & \multirow{2}{*}{$\begin{array}{l}\text { Médi } \\
\text { a }\end{array}$} \\
\hline & 1 & 3 & 5,5 & 8,5 & 15 & & \\
\hline $\begin{array}{l}\text { Curso(s) de } \\
\text { Extensão/Especialização }\end{array}$ & - & 4 & 3 & 4 & 1 & 12 & 6,5 \\
\hline Curso Superior de Tecnologia & 1 & - & 2 & 2 & - & 5 & 5,8 \\
\hline Bacharelado & 4 & 3 & 2 & - & - & 9 & 2,7 \\
\hline Licenciatura & - & - & 1 & 1 & - & 2 & 7,0 \\
\hline Pós-graduação Lato Sensu/MBA & 1 & 7 & 4 & 3 & 2 & 17 & 5,9 \\
\hline Mestrado Stricto Sensu & - & - & - & 1 & - & 1 & 8,5 \\
\hline $\begin{array}{l}\text { Não houve continuidade de } \\
\text { estudos }\end{array}$ & 3 & 6 & 4 & - & - & 13 & 3,3 \\
\hline Total & 9 & 20 & 16 & 11 & 3 & 59 & \\
\hline
\end{tabular}

Fonte: Elaborada pelos autores, 2017.

Observação: Valores aplicados tomando por referência a faixa salarial, a saber: $1=$ Até 2 salários; $3=$ acima de 2 até 4 salários; 5,5 = acima de 4 até 7 salários; 8,5 = acima de 7 até 10 salários

Revista ENIAC Pesquisa, Guarulhos (SP), V.7, n.1, jan.- jun. 2018. 
Para os Tecnólogos os resultados são bem diferentes. O único curso acadêmico que proporcionou melhora da média da faixa salarial foi o de Pós-Graduação Lato Sensu/MBA, porém em escala inferior aos Bacharéis (Tabela 10).

Tabela 10 - Relação entre outras formações e faixa salarial dos Tecnólogos

\begin{tabular}{|c|c|c|c|c|c|c|}
\hline \multirow[b]{2}{*}{ Curso/Formação } & \multicolumn{4}{|c|}{ Valores* } & \multirow{2}{*}{ Média } & \multirow{2}{*}{ Tota } \\
\hline & 1 & 3 & 5,5 & 8,5 & & \\
\hline $\begin{array}{l}\text { Curso(s) de } \\
\text { Extensão/Especialização }\end{array}$ & 4 & 6 & 2 & $-* *$ & 2,8 & 12 \\
\hline Curso Superior de Tecnologia & 2 & 1 & - & - & 1,7 & 3 \\
\hline Bacharelado & 4 & 3 & - & 1 & 2,7 & 8 \\
\hline Licenciatura & - & 1 & - & - & 3,0 & 1 \\
\hline Pós-graduação Lato Sensu/MBA & 1 & 4 & 4 & - & 3,9 & 9 \\
\hline $\begin{array}{l}\text { Não houve continuidade de } \\
\text { estudos }\end{array}$ & 5 & 9 & 3 & - & 2,9 & 17 \\
\hline Total & 16 & 24 & 9 & 1 & & 50 \\
\hline
\end{tabular}

Fonte: Elaborada pelos autores, 2017.

Observação: Valores aplicados tomando por referência a faixa salarial, a saber: $1=$ Até 2 salários; $3=$ acima de 2 até 4 salários; 5,5 = acima de 4 até 7 salários; 8,5 = acima de 7 até 10 salários

\section{CONSIDERAÇÕES FINAIS}

Esta pesquisa exploratória quantitativa teve o objetivo principal de comparar o perfil e a trajetória dos profissionais que concluíram Cursos de Bacharelado e, igualmente, aqueles que concluíram Cursos Superiores de Tecnologia na área de Gerenciamento e Administração em Instituições de Ensino Superior (IES) privadas com vantagem competitiva em seus preços. Os dados foram coletados por meio de questionário fechado online, enviado a profissionais graduados em instituições privadas, que praticam gestão de preço competitivo, entre os anos de 2004 e 2015.

O principal motivador para ingressar no ensino superior foi buscar a melhoria de cargo ou salário. Embora o nível de insatisfação seja relevante, o curso não atendeu ou atendeu parcialmente as expectativas de $38 \%$ dos respondentes e apenas um afirmou que a formação não gerou qualquer benefício.

Dos respondentes, $78 \%$ afirmaram que tiveram melhoria de cargo ou posição após a formação. No que se refere aos cargos ocupados, $29 \%$ encontram-se em alguma posição de gestão, seja como subordinado de alguma organização ou no próprio negócio. Com

Revista ENIAC Pesquisa, Guarulhos (SP), V.7, n.1, jan.- jun. 2018. 
relação aos rendimentos mensais um terço dos respondentes possui remuneração superior a quatro salários mínimos.

A taxa de profissionais que tiveram período superior a seis meses sem ocupação profissional remunerada é de $23 \%$. Sendo que $77 \%$ tiveram no mínimo uma troca de emprego após a formação. Ao analisar as motivações ou causas das mudanças $70 \%$ das respostas indicavam a oportunidade de alguma melhoria salarial ou profissional. Estas informações permitem verificar a capacidade de se recolocar profissionalmente.

Os resultados comprovaram que o grau acadêmico de ensino superior promove diferenciação na carreira do profissional da área de Gerenciamento e Administração, formado em instituições privadas com gestão de custo competitiva, auxiliando na definição do cargo ocupado, do salário e na busca de colocação no mercado de trabalho.

Outras considerações podem ser feitas a partir da afirmação de diferenças e coincidências entre o perfil dos dois públicos, especialmente no que se refere à idade ou intervalo de tempo entre o término do ensino médio e o início da graduação, cargos e salários e cultura familiar. Testes realizados por meio de cálculos do intervalo de confiança comprovaram que o perfil dos dois públicos é semelhante. Porém os benefícios obtidos no mercado são bem diferentes.

O perfil social dos Bacharéis e dos Tecnólogos é semelhante. Ambos os grupos já estão inseridos no mercado de trabalho antes de iniciar a formação, custeiam a maior parte do curso de graduação, buscam melhoria de cargo e salário no mercado de trabalho, não possuem cultura familiar universitária e o período de ingresso no ensino superior é similar.

Os grupos apresentam diferenças após a formação. Comprovou-se que os Bacharéis obtêm vantagens com relação aos salários e cargos ocupados. Ao adquirirem novos títulos acadêmicos ou especializações, a média salarial dos tecnólogos permanece similar, enquanto os Bacharéis passam a ter rendimentos maiores.

Para ambos os egressos, o índice de profissionais em cargo de liderança (29\%), com salários superiores a quatro salários mínimos (33\%) é baixo, permitindo afirmar que existem barreiras para a evolução profissional e intelectual deste público. Esta pesquisa refere-se ao público que, em busca de melhoria de cargo e salário, investiu percentual relevante de seus rendimentos em uma instituição de ensino superior privada.

Outro questionamento instigado por esta pesquisa concerne à área de formação. A análise dos dados estatísticos oficiais do Censo da Educação Superior (INEP, 2014) Revista ENIAC Pesquisa, Guarulhos (SP), V.7, n.1, jan.- jun. 2018. 
comprovou que a Área de Gerenciamento e Administração foi fortemente afetada por todo o processo de expansão do ensino superior. O setor privado explorou de modo considerável o potencial desta área no que se refere aos cursos de baixo custo e a possibilidade de atrair um público carente de reconhecimento intelectual, conforme apresentado por Almeida (2015), Bertero (2006), Prates e Silva (2015) e Barbosa (2014). Sabe-se que, apesar da expansão, apenas $18,1 \%$ dos jovens em idade ideal estão no ensino superior (IBGE, 2014) e mais de 70\% destes jovens encontram-se no setor privado.

Uma das comprovações desta pesquisa é que a democratização do ensino superior não aconteceu. Pois, ainda que esta população tenha obtido alguma melhoria social e cultural, manteve-se na base da pirâmide da colocação das classes sociais.

Bertero (2006) ao dissertar sobre os Bacharéis de administração inferiu que a grande maioria jamais ocuparia um posto de gestor, mesmo que de primeira linha ou de supervisão. Quando se amplia esta afirmação para os Tecnólogos da área de Gerenciamento e Administração os resultados são mais relevantes, pois mesmo aqueles que buscaram ampliar sua capacitação, adquirindo outras formações ou títulos acadêmicos, não obtiveram resultados positivos. Comprovou-se a afirmação de Barbosa (2015), identificando a inclusão de uma classe social antes excluída deste nível de ensino, porém os benefícios são questionáveis.

Pelos resultados desta pesquisa, abrem-se caminhos para outros questionamentos. O comparativo com instituições públicas, privadas confessionais ou comunitárias com foco em pesquisa forneceria dados para novas afirmações. O enfoque qualitativo permitiria se aprofundar a respeito de outras variáveis que envolvem este público, como, por exemplo, o entendimento dos motivos que os levaram a optar por determinado grau acadêmico.

A maior parte dos resultados desta pesquisa se mostra desfavorável para os profissionais da área de Gerenciamento e Administração oriundos de IES privadas de custo competitivo, seja Bacharéis ou Tecnólogos, especialmente no que se refere aos cargos e salários. Entretanto não seria prudente negligenciar os benefícios, reconhecidos e identificados pelos respondentes, a partir da formação adquirida. Portanto, a urgência apresentada é o aperfeiçoamento do processo de expansão iniciado, melhorando em escalas similares as oportunidades profissionais no mercado de trabalho e reduzindo o status de privilégio para aqueles que chegam a este nível de educação.

Revista ENIAC Pesquisa, Guarulhos (SP), V.7, n.1, jan.- jun. 2018. 


\section{REFERÊNCIAS}

ALMEIDA, Wilson Mesquita de. Ampliação do Acesso ao Ensino Superior Privado Lucrativo Brasileiro: um Estudo Sociológico com Bolsistas do PROUNI na Cidade de São Paulo. São Paulo. 294p. Tese (Doutorado em Sociologia), Universidade de São Paulo, São Paulo, 2012.

Os Herdeiros e os Bolsistas do PROUNI na Cidade de São Paulo. Educação Social, Campinas, v. 36, n. 130, p. 85-100, jan-mar. 2015.

AMORIM, Ricardo L. C; CAMPOS, André G.; GARCIA, Ronaldo C. (Eds.). BRASIL: O estado de uma nação. Brasília: IPEA, 2008.

ARANHA, Maria Lúcia de Arruda. História da educação e da pedagogia: geral e Brasil. 3. ed. rev. e ampliada. São Paulo: Moderna, 2006.

BARBOSA, Maria L. O. Expansão, Diversificação, Democratização: questões de pesquisa sobre os rumos do ensino superior no Brasil. Caderno CrH, Salvador, v. 28, n. 74, p. 247-253, maio/ago. 2015.

O ensino superior no Brasil: credencial, mérito e os coronéis. In: OLIVEIRA, Maria Ligia de (Org.). Ensino Superior: expansão e democratização. Rio de Janeiro: 7 Letras, 2014, p. 51-71.

BERTERO, Carlos O. A Docência Numa Universidade em Mudanças. Cadernos EBRAPE. v. 5, Edição Especial, p. 1-11, jan. 2007.

Ensino e Pesquisa em Administração. São Paulo: Thomson Learning, 2006. (Coleção Debates em Administração).

BRASIL. Portaria MEC n. 1.647/99, de 25 de novembro de 1999. Dispõe sobre o credenciamento de centros de educação tecnológica e a autorização de cursos de nível tecnológico da educação profissional.

DURHAM, Eunice R. Educação superior, pública e privada (1808-2000). In: BROCK, Colin; SCHWARTZMAN (Org.). Os Desafios da Educação no Brasil. Rio de Janeiro: Nova Fronteira, 2005, p. 197-240.

IBGE-Instituto Brasileiro de Geografia e Estatística. Síntese de Indicadores Sociais.

Revista ENIAC Pesquisa, Guarulhos (SP), V.7, n.1, jan.- jun. 2018. 
Brasil,

2015.

Disponível

em:

<http://www.ibge.gov.br/home/estatistica/populacao/condicaodevida/indicadoresmini mos/sinteseindicsociais2015/default_tab_xls.shtm>. Acesso em: 20 nov. 2016.

INEP - Instituto Nacional de Estudos e Pesquisas Educacionais Anísio Teixeira. Microdados Censo da Educação Superior. 2000-2014. Disponível em <http://dados.gov.br/dataset/ microdados-do-censo-da-educacao-superior >. Acesso em: 10 abr. 2016.

OLIVEIRA, Fatima B. SAUERBRONN, Fernanda Filgueiras. Trajetória, desafios e tendências no ensino superior de administração e administração pública no Brasil: uma breve contribuição. RAP - Revista da Administração Pública, Edição comemorativa, p. 149-170, 2007.

PAULA, Ana P. P.; RODRIGUES, Marco A. Pedagogia Crítica no Ensino da Administração: desafios e possibilidades. Revista de Administração de Empresas, Minas Gerais, v. 46, p. 10-22, Edição Especial, 2006.

PETEROSSI, Helena G. Subsídios ao estudo da Educação Profissional e Tecnológica. 2. ed. São Paulo: Centro Paula Souza, 2014, v. 1. (Coleção Fundamentos e Prática em Educação Profissional e Tecnológica) .

PRATES, Antônio A. P.; SILVA, Matheus F. Os efeitos diferenciais do tipo de instituição de ensino superior sobre o prestígio dos seus egressos no mercado de trabalho. In:

OLIVEIRA, Maria Ligia de (Org.). Ensino Superior: expansão e democratização. Rio de Janeiro: 7 Letras, 2014, p. 129-153.

REIS, Maurício C.; MACHADO, Danielle C. Uma análise dos rendimentos do trabalho entre indivíduos com ensino superior no Brasil. Rio de Janeiro: IPEA, 2015.

RISTOFF, Dilvo. Vinte e um anos de educação superior - Expansão e democratização. Cadernos do GEA, n. 3, p. 57, jan/jun. 2013.

SAMPAIO, Helena. Diversidade e Diferenciação no Ensino Superior no Brasil: Conceitos para discussão. Revista Brasileira de Ciências Sociais; v. 29, n. 84, p. 43-55, fev.2014.

TAKAHASHI, Adriana R. W. Cursos superiores de tecnologia em gestão: reflexões e implicações da expansão de uma (nova) modalidade de ensino superior em administração no Brasil. RAP - Revista de Administração Pública, v. 44. n. 2, p. 385-414, mar/abr.

Revista ENIAC Pesquisa, Guarulhos (SP), V.7, n.1, jan.- jun. 2018. 
2010.

TAKAHASHI, A. R.; AMORIM, Wilson A. C. Reformulação e expansão dos cursos superiores de tecnologia no Brasil: as dificuldades da retomada da educação profissional. Ensaio: Avaliação de Políticas Públicas em Educação, Rio de Janeiro, v. 16, n. 59, p. 207-228, abr/jun. 2008.

Revista ENIAC Pesquisa, Guarulhos (SP), V.7, n.1, jan.- jun. 2018. 